\title{
Changing times for scholarly communication: The case of the academic research video and the online video journal
}

\author{
Fernando Canet
}

How to cite this article:

Canet, Fernando (2019). "Changing times for scholarly communication: The case of the academic research video and the online video journal". El profesional de la información, v. 28, n. 4, e280406.

https://doi.org/10.3145/epi.2019.jul.06

Manuscript received on $19^{\text {th }}$ Oct 2018 Accepted on $17^{\text {th }}$ Jan 2019

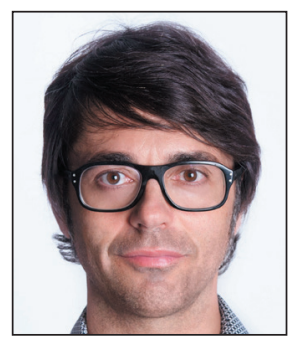

\section{Fernando Canet $\square$}

https://orcid.org/0000-0002-1455-9249

Universitat Politècnica de València

Facultad de Bellas Artes

Camino de Vera, s/n. 46022 València, Spain

fercacen@upv.es

\begin{abstract}
This paper aims to address the video as a new scholarly communication form, alternative to the traditional written paper. Although the use of video could be a worthwhile option for any field of study in which videographic practice would facilitate the communication of the research findings and thus enhance our understanding of them, this practice seems especially useful when the object of study itself is the audiovisual language. For this reason and because the number of media scholars communicating their research outputs in videos has increased in recent years to the extent of becoming a new trend, I focus on the exploration of this practice in this discipline. However, could the video meet academic standards, and thus be considered as a new scholarly form? If the answer is affirmative, what exactly makes a video academic? Offering some answers to these questions is the main purpose of this article, which reviews how the transition from the written paper to the audiovisual form is evolving. This exploration will include not only these types of videos but also the online journals that make the publication of such videos possible, thereby facilitating a study of how these online platforms allow new ways of communicating research outputs in academic contexts.
\end{abstract}

\section{Keywords}

Scholarly communication; Scholarly publishing; Video; Academic research video; Online video journal; Videographic practice; Audiovisual media; Online platforms.

\section{Introduction}

In times as volatile as those of the information age, the implications of the use of information and communication technologies for any field of society should be a constantly reviewed object of study. Scholarly communication itself is not immune to this volatility. In 2013, Jankowski and Jones co-edited a special issue of New media \& society on this topic, entitled "Scholarly publishing and the Internet", which sought to provide a panoramic view of how scholarly publishing and communication was evolving at that time. In short, the topics addressed in the four articles that gave shape to this thematic section were:

- an article by Pochoda (2013) comparing the new context of publishing with the traditional publishing form;

- a paper by Acord and Harley (2013) focusing on how new media technologies are useful for scholarly sharing practices;

- an article by Willinsky and Provençal (2013) exploring how digital innovations facilitate the ideals of learning;

- and an examination by Stewart et al. (2013) of the central role of academic publishers as intermediaries to exploit technological innovations and thus provide scholars with new Web 2.0 services. 
This article aims to offer a kind of update on these topics six years later with the exploration of a new scholarly communication form. In doing so, my focus will be on how the potential of technological innovations identified in the aforementioned articles has now become a reality (Stewart et al., 2013, p. 414). One of these new practices is using the video as an alternative form for the publication of scholarly research findings. I am not referring here to videos, for example, edited as supplementary material to published articles (videos that the authors can edit to introduce or summarize their articles, or that show them being interviewed), or to videos that document a laboratory research process, panels at conferences, or the like. ${ }^{1}$ These types of videos are beyond the scope of this article, which instead seeks to explore how the video, as a product in itself and not as additional material, may be suitable for publication

The use of video could be a worthwhile option for any field of study in which videographic practice would facilitate the communication of the research findings and thus enhance our understanding of them

in academic journals as an alternative form to the traditional written paper. Like other scholars who have written on this topic (Grant, 2016; Van-den-Berg; Kiss, 2016), I do not believe that the video will ever replace written articles as the dominant practice in research communication; nevertheless, this kind of scholarly work constitutes an interesting alternative to the established form.

The use of video could be a worthwhile option for any field of study in which videographic practice would facilitate the communication of the research findings and thus enhance our understanding of them. As Matias Pasquali suggests,

"[s]cientists began using moving images to record and describe their work almost as soon as the technology became available" (Pasquali, 2007). ${ }^{2}$

In his paper, Pasquali identifies the Journal of visualized experiments (JoVE) as a notable example of a PubMed-indexed video journal in the physical and life sciences. However, this practice seems especially useful when the object of study itself is audiovisual language. For this reason and because the number of media scholars communicating their research outputs in videos has increased in recent years to the extent of becoming a new trend, I will focus on the exploration of this practice in this particular discipline. Nowadays, digital editing systems and online sharing platforms give these scholars the option of becoming academic video-makers, making their own videos on their research on film, television or video games. To do this, they are putting into practice something that Raymond Bellour proposed back in 1975, in his article titled "The unattainable text", when he suggested the idea of taking film "as the medium of its own criticism" (Bellour, 2000, p. 27).

This proposal has been updated by Thomas Van-den-Berg and Miklós Kiss in their recent book Film studies in motion: From audiovisual essay to academic research video (Van-den-Berg; Kiss, 2016). In both the book's title and its conclusion, they specifically invite film scholars to put film studies "in motion". This open access e-book is an example of the recent relative boom in academic bibliography about "videographic film studies". Another example is the book co-written by Christian Keathley and Jason Mittell titled The videographic essay: Criticism in sound \& image (Keathley; Mittell, 2016), containing contributions by Eric Faden, Catherine Grant and Kevin B. Lee. It is also worth noting that the Summer 2017 issue of Cinema journal deals with "videographic criticism" in its "In focus" section, edited by Cinema Journal's online editor, Christine

Nowadays, digital editing systems and online sharing platforms give film, media and communication scholars the option of becoming academic video-makers, making their own videos on their research on film, television or video games

Becker. These three publications could be considered the contemporary descendants of Faden's pioneering article "A manifesto for critical media", written in 2008, and of a significant number of papers written since then by Grant (2014; 2016; 2017), Keathley (2011) Keathley and Mittell (2016), Álvarez-López and Martin (2014; 2015), Morton (2017) and Lavik (2012), among others. ${ }^{3}$

\section{Objectives and methodology}

This growing interest prompts various questions: Could the audiovisual form meet academic standards, and thus be deemed comparable with the traditional written paper? And consequently, could it be considered a new scholarly form? If the answer is affirmative, what exactly makes a video academic? This article thus aims to explore how the transition from the written paper to the audiovisual form is evolving, exploring the features that characterize this new scholarly form by comparing them with those of the traditional form. ${ }^{4}$ This conceptual discussion includes not only the features of this type of videos but also the online journals that make their publication possible, thereby facilitating a study of how these online platforms allow new ways of communicating research outputs in academic contexts.

With this goal in mind, I firstly follow Lluís Codina's methodological proposal called "systemized reviews in Human and Social Sciences" ${ }^{\prime}$ (Codina, 2018), in order to explore the published bibliography on the object of study proposed. Codina bases his proposal on the SALSA's framework (Grant; Booth, 2009) with the purpose to focus on the four steps through which to undertake the bibliography review: search, appraisal, synthesis and analysis (Codina, 2018). Scopus (Elsevier) 
and Web of Science (Clarivate Analytics) are the two main academic sources used in order to guarantee the relevance of the bibliography corpus analyzed. Secondly, I conduct case studies of three examples of what I call "online video journal". This sample is practically the full corpus of this kind of journals and certainly the most relevant examples either because of its pioneering status or because of its international popularity among the scholars that use the video as an alternative to the written paper. ${ }^{6}$ While Andrew Calabrese presented a case study of the electronic journal as a new way to publish in his article "Changing times for scholarly communication: The case of the electronic journal" (Calabrese, 1992), the online video journal is the case study in this article. Hence, the title of this article is an homage to Calabrese's article. In the past, scholars have often pointed out that in their respective moments they were in changing times (Acord; Harley, 2013; Nentwich, 2003); this continues to be true, because the changing times never end.

\section{Some initial steps}

The use of still frames and excerpts from media are often used in academic conferences or lectures as a complement to oral presentations. A pioneering example of this practice was the presentation by Stephen Mamber at the conference of the Society for Cinema Studies in 1989. As Robert Kolker recalls, he

"hooked up a computer, a laserdisk player, and a television monitor and controlled the images of the film on the laserdisk through the computer with a program he had written" (Kolker, 2004).

In these contexts, the visual or audiovisual content normally just takes the form of extracts from the media being studied, which are screened without editing. A further step is when these excerpts are edited and presented as a new production, in which the arguments and the content being analyzed are compiled together as parts of the same audiovisual product. The original purpose of such products was to be included in DVD releases of the films they analyzed as bonus material, like the DVD "extras" of the Criterion collection. Of particular note is the video made by Janet Bergstrom for Fox's special edition DVD of F. W. Murnau's Sunrise (1927), which subsequently led her to offer her first seminar on this practice in the winter of 2004. According to Bergstrom, "the idea was to provide a workshop-seminar where students could take advantage of our recent ability to 'quote' audio-visual media in (audio)visual essays they make themselves" (Stork, 2004, p. 1).

The film critic Edward Small, picking up on August Wilhelm von Schlegel's suggestion that the "theory of the novel should be a novel", suggests that the "theory of film should be a film". He proposes that

"certain kinds of film and video works constitute a mode of theory, theory direct, without the mediation of a separate semiotic system" (quoted in Alter, 2003, p. 13).

This "theory direct" is now a reality thanks to the possibilities that digital technology offers scholars, for whom Bellour's frustrations are no longer relevant, since

"the text of the film" is no longer "unattainable" because it is no longer "unquotable text" (Bellour, 2000, p. 20).

Keathley, paraphrasing Godard, asserts that

"film scholars can now answer images not only with words, but also with other images" (Keathley, 2011, p. 179).

And these images can be written as easily as if they were words, since scholars no longer need to involve anyone else in this practice; digital editing systems enable film scholars to personally edit their contributions using the audiovisual form, but without the complexities that this medium once entailed. This does not mean that skills in editing video are not necessary to develop these products; in this respect, minimum video production skills are required, and as these skills increase the medium will benefit.

Undoubtedly, one of the greatest pioneers in this practice is Eric Faden. He champions the use of what he calls "media stylos", invoking Alexandre Astruc's well-known metaphor of "caméra-stylo". Faden began to produce his media stylo proposals in the late 1990s. At that time, with the Internet only just beginning, academic conferences were, as he recognizes, the only places where he could show them. Instead of reading a paper, he would say nothing while he screened his twenty-minute video to the audience (Faden; Lee, 2016). Unlike the practice described at the beginning of this section, in which excerpts of films complement the oral presentation, in this case the edited video, as an autonomous product, takes over the presentation completely. Without a doubt, we can consider these videos pioneer examples of the new scholarly form that we are exploring in this article.

The advantages of digital technology have prompted some scholars in recent years to discuss the possibility of these kinds of videos becoming a new scholarly form for audiovisual media studies. A major starting point for this discussion has undoubtedly been the conferences organized by the Society for Cinema and Media Studies. The workshops titled "Video essays: Film scholarship's emergent form", hosted in Boston in 2012, and "Visualizing media studies", held in Seattle in 2014, can be considered two important milestones in the discussion of this new movement. Among the scholars who participated in these workshops, two figures stand out in particular: Grant and Keathley, both of whom are currently among the most enthusiastic supporters of this new academic practice.

Between the two conferences organized by Society for Cinema and Media Studies in the United States, another one on this topic was held in Europe. In November 2013, Martin and Álvarez-López organized the international conference 
and workshop "The audiovisual essay: Practice and theory", which was supported by Vinzenz Hediger and held at the Deutsches Filmmuseum -Deutsches Filminstitut in partnership with Film and Audiovisual Media at Goethe University (Frankfurt). Grant also attended this conference and, together with Martin and Álvarez-López, was co-editor of the proceedings, titled "The Frankfurt papers", which can be accessed at the Audiovisual Essay website.

Álvarez-López and Martin are two more well-known figures in this field. In addition to organizing academic events on this topic they have curated screenings, written several papers, and even produced examples of video essays. Álvarez-López was co-founder and co-editor of the Spanish film journal Transit: cine y otros desvíos. This journal, founded in 2009, was one of the first journals to include a section that collected video essays on cinema. Another journal that later also featured a video essays section is the academic journal Necsus: European journal of media studies, published by Amsterdam University Press $(A U P)$. This section is co-edited by Álvarez-López and Martin and it first appeared in the Autumn 2014 issue.

One of the partners that support Necsus is the European Network for Cinema and Media Studies (NECS). At the NECS 2014 conference held in Milan, Grant organized another workshop related to this topic, with the title "Videographic film and moving image studies: Audiovisual approaches to audiovisual subjects in research, publishing and teaching". Martin was one of the scholars invited to participate in this workshop; another was the also well-known American scholar Mittell, who also recently collaborated with Keathley on the book mentioned in the introduction. Both Keathley and Mittell are currently leading a pair of two-week workshops on videographic criticism at Middlebury College in Vermont (20172018). Previously, in June 2015, they hosted another workshop, titled "Scholarship in sound and image", which was the inspiration for their book.

\section{Online video journal (OVJ)}

Whilst previously viewing possibilities were limited to DVD and screenings at academic conferences as noted above, online video sharing platforms have now made much broader dissemination possible. The most well-known online platforms are YouTube and Vimeo, both of which first appeared in the mid-2000s and are now very popular. Among the advantages offered by these platforms is the possibility of creating thematically focused groups. In 2011, Grant, making use of this option, established Audiovisualcy, an online forum on Vimeo for videographic film studies, conceived as a site for sharing video essays about films. While by May 20, 2015, 650 videos had been shared on this forum, by December 28, 2018, that number had increased to 1,906. This increase of over 1,200 videos in three and a half years reflects the growing interest in this form of communication. Audiovisualcy was created as a complement to Grant's previous online project Film studies for free. Like any social media network, these sites invite their users not only to share content but also to offer their comments and evaluations of the content of others, while encouraging them to contribute to their dissemination, all with the intention of fostering debate and interaction among members of the online community.

With the intention of vesting this project with academic status and guaranteeing its scholarly rigor, Grant, in conjunction with Keathley and Morton, launched a new online video journal on March 20 ${ }^{\text {th }}, 2014$, called [in] Transition (Journal of videographic film \& moving image studies). The journal is a collaborative project between the Society for Cinema and Media Studies and MediaCommons Press, and was made possible thanks to the convergence of diverse interests. The role of Mittell as project manager of the MediaCommons project, an academic network for media scholars under the leadership of Kathleen Fitzpatrick and Avi Santo, was a central factor in this convergence. As Mittell notes, in 2013

"Drew Morton reached out to MediaCommons to propose starting a journal of video essays", and he knew that Keathley and Grant "had been discussing starting a similar journal on their own" (Mittell, 2017, p. 138).

He subsequently invited Becker, Cinema journal's online editor, to join the project as well. Becker happily accepted his invitation because she and Cinema journal editor Will Brooker had been thinking about how to expand the influence of their journal beyond the print medium, and this online project fitted perfectly with their plans
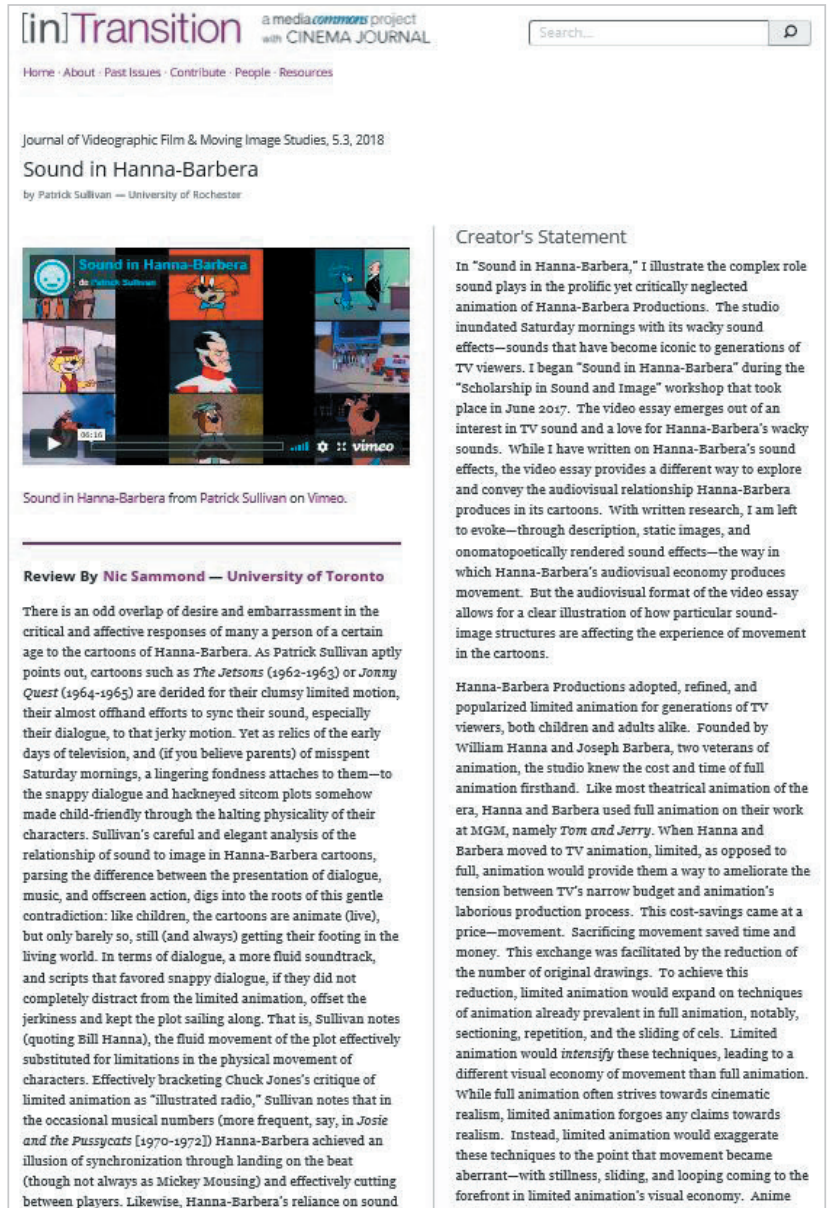

Figure 1. Example from one [in]Transition's issue $(5.3,2018)$

http://mediacommons.org/intransition/sound-hanna-barbera 
to explore new scholarly forms. As noted above, this case thus constitutes an example of the vital importance of the willingness of academic publishers to take advantage of the possibilities of new media.

Another precursor to this new enterprise was the section created in the Fall 2009 issue of the journal Mediascape (inspired by Faden's manifesto mentioned above), containing videos that were first screened at UCLA's Critical media film festival in April 2007. For Faden,

"with the electronic journal's invention the media stylo increasingly equates to the scholarly journal article" (Faden, 2008, np).

In the cases of Mediascape, and the aforementioned Transit and Necsus, the option to publish videos coexists with the traditional option in a section in the respective journals. In 2012, Visual communication became another journal in which visual essays coexist with the conventional research paper. In addition, a third kind of paper can be published in this journal: "reflective papers", which are essays written not so much by theorists as by practitioners of visual communication who document and reflect on their practice in writing. Along the same lines, Screenworks invites contributors to share practice research in communication by publishing not only research statements but, especially, audiovisual works resulting from the research. The idea of Screenworks was proposed in 2006 by Jon Dovey and its current editor Charlotte Crofts, and it was originally distributed as a DVD with The journal of media practice by Intellect Books. ${ }^{7}$ The website version of Screenworks was launched in 2016, turning it into a pioneering example of a peer-reviewed video online journal on practice research in film and screen media.

However, it could be argued that Audiovisual thinking is the true pioneer among peer-reviewed online video journals from the theoretical and analytical perspective. This journal presents research outputs on media communication entirely through the publication of videos instead of traditional papers. The first issue of this biannual online video journal was launched in July 2010 and the last, its seventh issue, was published in 2014. According to Inge Sørensen, this unique editorial project was started by five PhD students from Denmark, Sweden, Finland and Israel. Work on the journal suffered substantially when its founders all finished their PhDs and took up full-time teaching positions in 2013/2014. Currently (again according to Sørensen) they are trying to resurrect the journal, applying for funding to cover the cost of the extensive structural work that the website needs to continue. ${ }^{8}$

Eriksson and Sørensen explain that from the outset one of the main aims of this journal was to develop

"a respected, accredited and acknowledged academic discourse and method of delivering and disseminating research results" (Eriksson; Sørensen 2012, p. 2).

To achieve this level of scientific rigor and thus ensure recognition as a traditional academic journal, a defining feature of the projects [in]Transition, Screenworks and Audiovisual Thinking is that they are peer-reviewed. In all three cases, their editors highlight this feature, emphasizing its importance. It therefore seems clear that these alternative publications need to emulate the standards of the traditional journal if they want to attain academic status. Numerous scholars have suggested that the peer-reviewed process is the main accepted method to guarantee the quality of scholarly publications (Acord; Harley, 2013; Arms; Larsen, 2007; Calabrese, 1992; Harley et al., 2010; Stewart et al., 2013), and it would seem reasonable that the same method should apply to this new form of scholarly communication. Thus, on the Screenworks website it is stressed that

"[w]hat is unique about Screenworks is that the work is subject to academic peer review, just as an academic journal article would be, thus providing evidence of the impact, significance, originality and rigour of the practice as research."

Pascuali also believes that the quality of video submissions depends on the peer-review process (Pasquali, 2007).

However, the editors of Screenworks and [in]Transition go beyond the traditional blind peer-review process, following the open review policy publishing in both cases the reviews. Even [in]Transition the identity of both reviewers and authors is disclosed. 
Yet this proposal is not new, as Harley and Acord have already reviewed innovative cases across disciplines in 2011. Later, they mention MediaCommons as an example in the media studies field where the open peer-review process has been proposed as an academic practice (Acord; Harley, 2013, p. 388). As Mittell notes, they

"launched MediaCommons Press as a site to publish drafts of scholarly writing, inviting open peer review via the platform CommentPress" (Mittell, 2017, p. 138). ${ }^{9}$

It is not easy to find more contemporary examples of this practice, which seems to confirm what Acord and Harley anticipated in their article when they suggested that

"open peer review will not gain widespread traction across disciplines..." (Acord; Harley, 2013, p. 388). ${ }^{10}$

Another way of ensuring academic status is setting up an editorial/advisory board for the journal. For instance, as the editors of Audiovisual thinking themselves recognize, the support of leading academics was very important for the journal to achieve academic standards of quality (Eriksson; Sørensen, 2012, p. 2). Similarly, [in]Transition has the support of a long list of well-known scholars, whose presence also endorses the quality of the project. This journal also won the 2015 Anne Friedberg innovative scholarship award of distinction given by the Society for Cinema and Media Studies, constituting another means of obtaining the necessary approval of the academic world.
I propose the term "online video journal" (OVJ) for these kinds of online journals that make it possible to publish videos as a new scholarly form, while guaranteeing academic status by observing the rules that regulate traditional publications, including the establishment of a peer review process and a recognized editorial board

I propose the term "online video journal" (OVJ) for these kinds of online journals that make it possible to publish videos as a new scholarly form, while guaranteeing academic status by observing the rules that regulate traditional publications, including the establishment of a peer review process and a recognized editorial board. However, I have thus far been able to find any cases of such journals being indexed, or even any information to suggest that indexing is being pursued. Given that indexing is a key criterion in the evaluation of the impact and quality of a journal, this should be one of the most urgent matters for these innovative journals to address in their quest to achieve the level of academic excellence of the most prestigious traditional publications. ${ }^{11}$

Table 1. Main features of the journals object of study

\begin{tabular}{|c|c|c|c|c|c|c|c|}
\hline $\begin{array}{c}\text { Online video } \\
\text { journal }\end{array}$ & Editorial team & Supported by & $\begin{array}{c}\text { Date/ } \\
\text { Frequency }\end{array}$ & $\begin{array}{l}\text { Peer-re- } \\
\text { viewed }\end{array}$ & $\begin{array}{l}\text { Editorial/Ad- } \\
\text { visory board }\end{array}$ & $\begin{array}{l}\text { Indexed by } \\
\text { Scopus/WoS }\end{array}$ & $\begin{array}{c}\text { Ranked by } \\
\text { SJR/JCR }\end{array}$ \\
\hline [in]Transition & $\begin{array}{l}\text { Catherine Grant, } \\
\text { Chiara Grizzaffi, } \\
\text { Christian Keathley, } \\
\text { Drew Morton }\end{array}$ & $\begin{array}{l}\text { MediaCommons and } \\
\text { Cinema journal (Society for } \\
\text { Cinema and Media Studies) }\end{array}$ & $\begin{array}{l}2014 \text { to } \\
\text { present } \\
4 \text { issues per } \\
\text { year }\end{array}$ & Yes (open) & Yes (44) & No & No \\
\hline Screenworks & $\begin{array}{l}\text { Charlotte Crofts, } \\
\text { Elan Gamaker, } \\
\text { Lucy Leake, } \\
\text { Nariman Massoumi, } \\
\text { Alexander Nevill }\end{array}$ & $\begin{array}{l}\text { Digital Cultures Research } \\
\text { Centre at the University of } \\
\text { the West of England, Bristol }\end{array}$ & $\begin{array}{l}2016 \text { to } \\
\text { present } \\
3 \text { issues per } \\
\text { year }\end{array}$ & Yes (open) & No & No & No \\
\hline $\begin{array}{l}\text { Audiovisual } \\
\text { thinking }\end{array}$ & $\begin{array}{l}\text { Thommy Eriksson, } \\
\text { Oranit Klein Shagrir, } \\
\text { Inge Sørensen, } \\
\text { Petri Kola, } \\
\text { Sanna Marttila }\end{array}$ & & $\begin{array}{l}2010-2014 \\
7 \text { issues in } \\
\text { total }\end{array}$ & Yes & Yes (5) & No & No \\
\hline
\end{tabular}




\section{What videos might be published by OVJs?}

As Becker points out, their challenge was not only to work out

"what kind of platform could best host videographic content", but also "how such scholarship could be evaluated in ways comparable to the long-accepted high standards of print publication that Cinema journal represented" (Becker, 2017, p. 127).

The first part of this challenge was already met with the launch of [in]Transition, but the second part is not resolved yet. It seems logical to assume that the academic video should be regulated, like traditional journals, according to the same criteria that determine whether a written paper is to be deemed academic.

In this respect, all the journals analyzed here stress the same central idea: the video, like the written paper, should offer new knowledge about its subject. Especially relevant in this regard is the rationale of the editors of Audiovisual thinking, whose "Academic video manifesto" sets out their requirements for contributors. Among the requirements specified, one that I would argue is central for a video to be deemed an academic contribution is the requirement that it

"disseminate new observations, knowledge, insights or theories [...]."

Keathley and Mittell underlines this requirement when he suggests that

"the ultimate goal of videographic work may be to produce scholarly knowledge about a particular media object of study" (Keathley; Mittell, 2016, np).

Other conditions stipulated by the editors of Audiovisual thinking include the requirement to

"acknowledge previous knowledge, insights or theories" and, obviously, to "credit all sources and references [...]".

As with written papers, it is not enough merely to produce new contributions; they should also be contextualized in relation to the previous knowledge already generated in any specific field of study. Needless to say, all sources and references used in the video should be cited, both at the moment when the source is quoted and at the end of the video in the form of a works cited list.

This new knowledge and its theoretical framework should be communicated through a clear and structured argument. Such clarity should be another essential condition to avoid ambiguous messages that could be prone to various interpretations. The editors of Audiovisual thinking acknowledge that they often had problems determining how to interpret what the authors wanted to communicate in their videos, and needed to confirm with other editors whether they were interpreting it in the same way (Eriksson; Sørensen, 2012, p. 7). I believe that in an academic context there should be no room for openness to a broad range of possible readings. It should not be a place for Umberto Eco's well-known idea of "open work", which invites readers to endow the work with their own interpretation, so that the meaning of any work depends not on its author but on each potential reader. In an academic context, the meaning of the text should depend entirely on the authors as a result of their research process, which may be corroborated or refuted but never misinterpreted by their fellow scholars.

According to Van-den-Berg and Kiss,

"the idealized form of academic research in an audiovisual wrapper [is an] autonomous and explanatorily argumentative research video" (Van-den-Berg; Kiss, 2016).

Kiss has already underlined the benefits of videos as standalone products (Kiss, 2014). However, the editors of both Screenworks and [in]Transition ask contributors to submit the video together with a write-up. The editors of Screenwor$k s$ request a statement of up to 2,000 words in which the author

"should outline Research Questions, Context, Methods, Outcomes and Impact [...]",

whereas [in]Transition's editors ask for a

"300-1000-word supporting statement that articulates the research aims and process of the work as well as the ways in which those aims are achieved in the audiovisual form".

It seems that this "research statement" is requested by both journals because the videos do not yet meet this academic criterion on their own.

\section{[in]Transition's editors suggest that}

"each video selection will normally be accompanied by a short critical essay that explains and justifies the work in two ways: for its creative use of multi-media tools; and for the way it creates a 'knowledge effect' - that is, for its impact as scholarship".

Although video essays currently require such explanation in both these ways, the trend should be toward producing videos that meet both requirements by themselves,

- firstly, because in watching the video we should be able to recognize how the video works, i.e. how the audiovisual form has been articulated in order to convey the "knowledge effect"; and 
- secondly, because the video itself, as an autonomous product like the written paper, should communicate this effect without the help of complementary textual information.

In addition, these two ways suggested remind me of the relationship between content and form. The content of these kinds of videos, if they are to be deemed academic products, should be the same as that of traditional written papers. This is the necessary condition for achieving the mentioned "knowledge effect" and consequently for their "impact as scholarship". Conversely, the form is what differentiates the new from the traditional approach, the traditional being characterized by written expression, whilst the new is characterized by audiovisual expression. Thus, while the content should be the same, what differs is the way in which that content is communicated.

\section{The audiovisual form: Defining academic research videos (ARV)}

As Eriksson and Sørensen recognize, responses to this new scholarly form have been ambivalent, as

"whilst comments and feedback from the research community on the activities of Audiovisual thinking have been overwhelmingly supportive, enthusiastic and positive, others have dismissed academic video as, at best, ineffectual, impractical and fanciful" (Eriksson; Sørensen, 2012, p. 2).

Faden acknowledges this his video presentations at academic conferences were met with the same ambivalent response $(2016, \mathrm{np})$. This ambivalence is not something new, as throughout history we have seen how innovative proposals have always had as many detractors as proponents. In any transition from one medium of expression to another, it is common to find positions rejecting the main features that define older forms because they are deemed to be limiting. The champions of this tendency express opposition to the dominant form and commonly propose to overcome its limitations by supporting creativity. Currently, Álvarez-López and Martin can be considered the main champions of this tendency, as they stress both the need

"to assert and demonstrate that seemingly 'purely' poetic forms can carry intellectual ideas and embody practices of scholarly research" and "the constitutively creative aspect of essayistic forms when they are forged in image and sound" (Álvarez-López; Martin, 2014, np).

Keathley posits a distinction between "explanatory" and "poetic" modes (Keathley, 2011). In the poetic mode, images, sounds and even music, along with the way these resources are articulated in the editing process, play the central role in the construction of meaning. In this mode, the discourse is developed without the support of an explanatory voice-over, as image and sound are the principal resources used. Thus, since words are central in written essays, one tendency is to avoid them by focusing exclusively on the power of the images. This is the paradoxical aspect of the voice-over in audiovisual essays, as although it may be one of the easiest ways to convey ideas in the audiovisual medium, it is at the same time the main strategy rejected by the champions of this tendency. For instance, Martin warns of its overuse, pointing out that

"the voice of the critic speaks - sometimes literally reads - a verbal text [...] the voice 'leads'. It is the voice which has authority - more than the original images and sounds of the movie. There is something frustrating, even wrong about this" (Martin, 2010, np).

Conversely, it is the voice-over the main resource that guides the creative process in the explanatory mode. As Keathley notes, in this mode

“images and sounds [...] are subordinated to explanatory language" (Keathley, 2011, p. 181).

This proposal brings us closer to Michel Chion's idea of vococentrism, according to which the human voice dominates and guides the creation of audiovisual production (Chion, 1999).

We are currently transitioning from the traditional to the new form, a process reflected in the name of the journal [in]Transition. This transition should be approached from a constructive perspective, so that, instead of systematically rejecting anything associated with the traditional form, we can explore the possibilities of the new form with an open mind. The main possibility of the audiovisual form is the one that allows the combination of the verbal and visual contents. The importance of this combination is highlighted by several scholars:
We are currently transitioning from the traditional to the new form, a process reflected in the name of the journal [in]Transition. This transition should be approached from a constructive perspective, so that, instead of systematically rejecting anything associated with the traditional form, we can explore the possibilities of the new form with an open mind

“...what excites and compels me about the possibilities digital video essays offer [...] are precisely their new or expanded forms of juxtaposition of audio-visual material with text [...]" (Grant, 2016, np);

"...it is this extraordinary combination...that marks the best video essays" (Keathley, 2011, p. 183);

"in the digital film criticism that I have in mind, however, text and image are carefully coordinated or 'co-written" (Lavik, 2012, p. 7). 
It is enlightening to compare Lavik's idea of "co-writing" with Andre Bazin's notion of "horizontal" montage. According to Bazin, in the new notion of montage that Chris Marker brings to his films,

"a given image doesn't refer to the one that preceded it or the one that will follow, but rather it refers laterally, in some way, to what is said" (2003, p. 44).

Bazin made these observations in his article for France-observateur on Marker's Letter from Siberia, published in 1958. One of the reasons behind this relationship in Marker's work is his critical engagement with the images. In his films, words are related to images because he focuses on how images work. For instance, the main subject of his movie Sans Soleil (1983) is not so much memory as how images represent memory. However, he expresses not only how images represent memory but also, very importantly, his personal interpretation of this process through suggestive forms of voice-over articulation. In developing this technique, Marker takes full advantage of the multitrack feature of cinema and therefore of the creative potential offered by the relationship between the two tracks, visual and verbal. Bazin saw great value in the dialectic between word and image proposed by this French filmmaker.

Hence the exploration of the combination of the verbal and visual contents seems central, becoming a challenge to find the appropriate balance between both elements in each production in order to properly convey the academic contents. Since the novelty lies not in the medium itself but in turning this medium into a new scholarly form, we need to explore how to manage the features that characterize this new form in order to communicate academic content as effectively as possible. Highly relevant in this sense is the opening question posed by Van-den-Berg and Kiss in their book:

"How can the traits and rhetoric of a traditionally text-based scholarly work, characterized by academic lucidity and traceability of information and argumentation, be optimally incorporated and streamlined into an autonomous, audiovisual container?" (Van-den-Berg; Kiss, 2016, np).

Van den Berg and Kiss made their own video in 2013 titled (un)reliable (un)reliability - or, Perceptual subversions of the continuity editing system. This video includes an introduction, contextualized thesis, theoretical framework, case study, and conclusion. The authors adapted these dense textual passages to the audiovisual form using both voice-over and on-screen written text, suggesting that our goal should not be to eliminate such content, which gives the video its academic status, as to find creative ways to adapt it to a multimodal language.

But the adaptation of textual material to the audiovisual medium is not the only question we should be exploring. We should explore others for which adaptation is not necessary because the materials are already audiovisual. I am referring here to videos related to the object of study that could help us contextualize it theoretically. For example, if our intention is to make a video about the TV Series The wire, we could quote ideas from Mittell's paper "The wire as complex TV". This paper, presented at The wire conference Panel 2: Seriality and narrative experience, hosted by the Heyman Center for the Humanities at Columbia University (April 8-9, 2016), was recorded thereby its contents can be used as audiovisual quotation. We could even explore the medium to create our own audiovisual content; continuing with the same example, we could set up an interview with Mittell by Skype to discuss questions related to The wire. The Skype interview would be recorded and we could likewise use this material for our own audiovisual product. Moreover, of course, we could record ourselves explaining our theories in relation to The wire, thereby inscribing our authorial figure in the video not only through voice-over but also by making our figure visible - that is, by our performance.

However, this new medium also raises problematic issues of copyright. Would we need to ask for Mittell's permission to use his image? Indeed, should we ask permission from the The wire's producers to use excerpts from the series? Several scholars have addressed such questions (Eriksson; Sørensen, 2012; Lavik, 2012; McWhirter, 2015; Van-den-Berg; Kiss, 2016, np). Mittell himself points out that

“...videographic criticism raises key issues around notions of ownership, authorship, originality and ethics” (2016).

Faden even edited a video titled A fair(y) use tale, in which he outlines the notion of copyright and the associated concept of "fair use"12 through the ironic use of snippets from animated Disney films. Copyright may initially be perceived as very limiting, as if we cannot quote the object of study, there is no point at all to the videographic process. Editors of traditional journals encourage authors to obtain permissions from copyright holders to reproduce still frames from the films their submissions analyze. The same approach could be taken for audiovisual essays; however, as Mittell notes, requests will probably be declined in most instances, particularly if the owner is a commercial media company (2016). 
Fortunately, we have other options that do not render us dependent on the economic goodwill of others, related to the "fair use" of the content appropriated. The "fair use" initiative, which is regulated by the American copyright law, justifies the use of excerpts of copyright material under certain circumstances. Examples of these circumstances are outlined on the [in]Transition website:

"[I]f such quotation or remix is necessary to a scholar's argument, if the quotation or remix serves to support a scholar's original analysis or pedagogical purpose, and if the quotation or remix does not unduly harm the market value of the original".

Since the first two situations reflect the very reasons for quoting the object of study and, in most cases, such quoting would not cause undue harm but probably have quite the opposite effect (as MediaCommons notes, "the scholarly quotation [...] enhances the value and cultural currency of objects of study"), it can be argued that videographic works in academic contexts are protected by the principles of "fair use". Moreover, in the case of the European context, as Lavik points out,

"European legal systems [also] give protection for the use of copyrighted materials for critical and educational aims" (Lavik, 2012, p. 9).

Eriksson and Sørensen support this idea, identifying Sweden as an example of a European country where copyright laws are permissible where research and educational purposes are concerned (Eriksson; Sørensen, 2012, p. 11). ${ }^{13}$

I have purposefully left the naming of these kinds of videos to this final section, because I felt it necessary first to outline their features and establish their context of application. Thus, having defined their nature and context, their name and definition may be easier to justify. The context is even more important for this justification than their nature, because the context plays a decisive role in determining their features. Thus, the academic context, wherein these videos fulfill their purpose, has been central to the definition of their features in this article, as it will be now to the name given to them. I therefore suggest looking to the subtitle of the journal Audiovisual thinking for our name for this type of product: the Journal of academic videos, and refer to this scholarly form simply as "academic videos". The use of "academic" achieves two objectives:

- first, it restricts these videos to their particular context, which is very important because, as we have seen, that context determines their features; and

- second, it differentiates them from other types of audiovisual proposals, like the video essay, which may be considered points of reference but not the same type of product.

However, we need to distinguish within the academic community between those videos made for teaching purposes from those that are the result of a research process. For this reason, I believe it is necessary to add the term "research" to the name, so that this new scholarly form is referred to as "academic research video" (ARV).

At this point, I should acknowledge that my proposal here, albeit unconsciously, has taken the direction hinted at in Van-den-Berg and Kiss's book subtitle: From audiovisual essay to academic research video, which invites us, as scholars, "[to] move towards the possibility of autonomous argumentative academic research video",

which they define as a kind of audiovisual work that

"will introduce a thesis, place this within a broader context, develop a theoretical notion and argument with an array of both aural as well as visual means, employing a full-bodied and standalone (video) 'text' to represent the analytical findings taken from a (film) 'text'" (Van-den-Berg; Kiss, 2016, np).

\section{Conclusions}

I fully endorse Van den Berg and Kiss's definition. We are currently in a transitional moment when we can find examples that are not yet mature, which are still far away from realizing all the objectives they propose. However, we should embrace their proposal as a challenge to guide our own theoretical and practical efforts. We should recognize that for a videographic work to be considered an academic research video, it must meet the standards of the academic world. As scholars, we are all responsible for rising to this challenge: both the authors who must meet these standards in their research communication, and the editors and reviewers who must ensure that those standards are met. In this regard, academic rigor is required to ensure the quality of online video journals, so that they may be deemed comparable to traditional journals.

This goal is not necessarily incompatible with finding creative ways to communicate the academic content in audiovisual form. The audiovisual medium and the audiovisual quotation fit together perfectly because both speak the same multimodal language. However, the quotation and manipulation of the object of study is not enough to deem a video an academic work, which must also include dense academic textual content. It is precisely this content that requires solutions that are more creative. We should address this challenge not only through the effective combination of images or the appropriate articulation of words, but also through the balanced combination of these two elements. Exploring new ways to bring images and words into dialogue with each other might thus allow us both to take full advantage of the expressive potential of the medium and to communicate academic content with fewer restrictions. 
Likewise, the exploration of a medium point on the continuum between the explanatory and poetic modes might allow us the opportunity to find creative ways of structuring academic content. Since the audiovisual form is the language of the academic research video, we are invited to explore that form's artistic possibilities. However, given that to focus only on this aspect would undermine the academic status of our work, we are also invited to explore how to take advantage of this artistic potential in order to communicate the academic content most effectively. In this way, we will be attentive to the aesthetic aspects of the videos while simultaneously guaranteeing their academic rigor.

I wish to stress once more that I do not believe that the audiovisual form will ever replace the conventional written paper. Its purpose instead should be to serve as an alternative to the traditional form for the objective of disseminating research within the academic community. This is possible with the support of academic publishers, whose willingness to take advantage of new media technologies is essential to the evolution of scholarly practices. In short, as part of this collective, we are invited to experiment with videographic audiovisual media studies through the production of academic research videos as a new scholarly communication form, which can be more effectively disseminated nowadays thanks to the recent proliferation of online journals that facilitate the academic level.

\section{Notes}

1. For further discussion about these types of videos and their research and educational applications, see Kousha, TheIwall \& Abdoli (2012), and Sugimoto and Thelwall (2013).

2. For further discussion about the possible advantages of using video to communicate scientific practices instead of written descriptions, see Pasquali (2007).

3. These scholars' proposals are in line with the Digital humanities manifesto 2.0, formulated by colleagues at the University of California, Los Angeles (UCLA). According to this manifesto,

"digital tools, techniques, and media have altered the production and dissemination of knowledge in the arts, human and social science" (2009).

Available at:

http://manifesto.humanities.ucla.edu/2009/05/29/the-digital-humanities-manifesto-20

4. It is beyond the scope of this article to provide an overview of the possible influences and precursors of this kind of video. Several scholars have already addressed this question. See, for example, Eriksson and Sørensen (2012) and, for a more in-depth study, Van-den-Berg and Kiss (2016).

5. In Spanish, "Revisiones sistematizadas en ciencias humanas y sociales" (ReSiste-CHS).

6. At the Spanish level, recently the journal Tecmerin. Journal of Audiovisual Essays has published its second issue (July 2019), being the first one published on December 2018. This journal is directed by professor Manuel Palacios and its managing editor is Vicente Rodríguez Ortega (both from the Universidad Carlos III de Madrid).

7. Vol. 1 was published with JMP, Autumn 2007 (8:2) and vol. 2 was published with JMP in December 2008 (9:3).

8. Quoted from personal correspondence with Inge Sørensen via email on August 1, 2017. I am grateful for her response to my email.

9. As Jankowski and Jones point out, previous Commons projects had been launched around 2012-2013. They mention MLA Commons, which was proposed by the Modern Language Association "to facilitate new formats in publishing" (2013, p. 349).

10. See their article for details of the reasons they give to support this statement. In addition, for more information on the open review process see "Open peer-review as multimodal scholarship", Shane Denson, Cinema journal, 2017.

11. For example, the Journal of visualized experiments (JoVE), which was mentioned in the introduction, is an indexed journal with impact factor.

12. As noted in Calabrese's article, "fair use" had already been introduced in previous contexts. One example he mentions is the Copyright Clearance Center (CCC), whose main purpose was to provide publishers with strategies to allow users to obtain more photocopies when "fair use" was exceeded (1992, p. 204).

13. For further information about this topic, visit the website of the Center for Media \& Social Impact, specifically the sections: "Code of best practices in fair use for the visual arts" and "Code of best practices in fair use for online video".

\section{References}

Acord, Sophia K.; Harley, Diane (2013). "Credit, time, and personality: The human challenges to sharing scholarly work using web 2.0". New media \& society, v. 15, n. 3, pp. 379-397.

https://cshe.berkeley.edu/publications/credit-time-and-personality-human-challenges-sharing-scholarly-work-using-web-20 https://doi.org/10.1177/1461444812465140

Alter, Nora M. (2003). “Memory essays". In: Biemann, Ursula (ed.). Stuff it: The video essay in the digital age, pp. $12-23$. Vienna: Springer. ISBN: 9783211203187 
Álvarez-López, Cristina; Martin, Adrian (2014). "Introduction to the audiovisual essay: A child of two mothers". Necsus, Autumn.

http://www.necsus-ejms.org/introduction-audiovisual-essay-child-two-mothers

Álvarez-López, Cristina; Martin, Adrian (2015). “The audiovisual essay as art practice”. Necsus, June 11. http://www.necsus-ejms.org/the-audiovisual-essay-as-art-practice

Arms, William Y.; Larsen, Ronald L. (2007). "The future of scholarly communication: Building the infrastructure for cyberscholarship". In: Report of workshop. Phoenix, AZ: National Science Foundation and Joint Information Systems Committee, April 17-19.

https://library.educause.edu/resources/2007/9/the-future-of-scholarly-communication-building-the-infrastructure-forcyberscholarship

Bazin, André [1958] (2003). "André Bazin on Chris Marker". Film comment, v. 39, n. 4, pp. 44-45.

Becker, Christine (2017). "Introduction: Transforming scholarship through [in]transition". Cinema journal, v. 56, n. 4, pp. 126-129.

https://doi.org/10.1353/cj.2017.0043

Bellour, Raymond (2000). "The unattainable text”. In: Penley, Constance (ed.). The analysis of film. Bloomington: Indiana University Press. ISBN: 9780253213648

Calabrese, Andrew (1992). "Changing times for scholarly communication: The case of the electronic journal". Technology in society, v. 14, n. 2, pp. 199-220.

https://spot.colorado.edu/ calabres/Changing\%20Times\%20for\%20Scholarly\%20Communication.pdf https://doi.org/10.1016/0160-791X(92)90004-T

Chion, Michel (1999). The voice in cinema. New York: Columbia UP. ISBN: 9780231108232

Codina, Lluís (2018). Revisiones bibliográficas sistematizadas: Procedimientos generales y framework para ciencias humanas y sociales. Barcelona: Master Universitario en Comunicación Social. Departamento de Comunicación. Universitat Pompeu Fabra. https://repositori.upf.edu/bitstream/handle/10230/34497/Codina_revisiones.pdf

Denson, Shane (2017). “Open peer-review as multimodal scholarship”. Cinema journal, v. 56, n. 4, pp. $141-143$. https://doi.org/10.1353/cj.2017.0046

Eriksson, Thommy; Sørensen, Inge E. (2012). "Reflection on academic video". Seminar.net. International journal of media, technology and lifelong learning, v. 8, n. 1, pp. 1-15.

https://journals.hioa.no/index.php/seminar/article/download/2399/2263

Faden, Eric S.; Lee, Kevin B. (2016). "In dialogue”. In: Keathley, Christian; Mittell, Jason (eds.). The videographic essay: Criticism in sound \& image. Montreal: Caboose. ISBN: 9781927852040

Faden, Eric S. (2008). "A manifesto for critical media". Mediascape: UCLA's journal of cinema and media studies. http://www.tft.ucla.edu/mediascape/Spring08_ManifestoForCriticalMedia.pdf

Grant, Catherine (2014). "How long is a piece of string? On the practice, scope and value of videographic film studies and criticism". In: Audiovisual essay conference: Practice and theory of videographic film and moving image studies. http://reframe.sussex.ac.uk/audiovisualessay/frankfurt-papers/catherine-grant

Grant, Catherine (2016). "Beyond tautology? Audio-visual film criticism”. Film criticism, v. 40, n. 1. https://doi.org/10.3998/fc.13761232.0040.113

Grant, Catherine (2017). "Star studies in transition: Notes on experimental videographic approaches to film performance". Cinema journal, v. 56, n. 4, pp. 148-158.

https://doi.org/10.1353/cj.2017.0047

Grant, Maria J.; Booth, Andrew (2009). "A typology of reviews: an analysis of 14 review types and associated methodologies". Health information and libraries journal, v. 26, n. 2, pp. 91-108.

https://doi.org/10.1111/j.1471-1842.2009.00848.x

Harley, Diane; Acord, Sophia K.; Earl-Novell, Sarah; Lawrence, Shannon; King, C. Judson (2010). Assessing the future landscape of scholarly communication: An exploration of faculty values and needs in seven disciplines. Berkeley, CA: Center for Studies in Higher Education, University of California.

https://escholarship.org/uc/item/15x7385g

Harley, Diane; Acord, Sophia K. (2011). Peer review in academic promotion and publishing: its meaning, locus, and future. Center for Studies in Higher Education, University of California, Berkeley, CA.

http://escholarship.org/uc/item/1xv148c8 
Jankowski, Nicholas W.; Jones, Steve (2013). "Scholarly publishing and the internet: A NM\&S themed section". New media \& society, v. 15, n. 3, pp. 345-358.

https://doi.org/10.1177/1461444812472098

Keathley, Christian; Mittell, Jason (eds.) (2016). The videographic essay: Criticism in sound \& image. Montreal: Caboose. ISBN: 9781927852040.

Keathley, Christian (2011). "La caméra-stylo: Notes on video criticism and cinephilia”. In: Clayton, Alex; Klevan, Andrew (eds.). The language and style of film criticism. London and New York: Routledge. ISBN: 9780415560962

Kiss, Miklos (2014). "The audiovisual research essay as an alternative to text-based scholarship". [in]Transition. http://mediacommons.org/intransition/2014/08/22/kiss

Kolker, Robert (2004). "Digital media and the analysis of film". In: Schreibman, Susan; Siemens, Ray; Unsworth, John (eds.). A companion to digital humanities. Oxford: Blackwell Publishing. ISBN: 9781405103213

Kousha, Kayvan; Thelwall, Mike; Abdoli, Mahshid (2012). "The role of online videos in research communication: A content analysis of YouTube videos cited in academic publications". Journal of the American Society for Information Science and Technology, v. 63, n. 9, pp. 1710-1727. https://doi.org/10.1002/asi.22717

Lavik, Erlend (2012). “The video essay: Th future of academic film and television criticism?”. Frames cinema journal. http://framescinemajournal.com/article/the-video-essay-the-future

Martin, Adrian (2010). "A voice too much". De Filmkrant.

http://reframe.sussex.ac.uk/audiovisualessay/reflections/adrian-martin-a-voice-too-much

McWhirter, Andrew (2015). "Film criticism, film scholarship and the video essay". Screen, v. 56, n. 3, pp. $369-377$. https://doi.org/10.1093/screen/hjv044

Mittell, Jason (2017). “Opening up [in]Transition's open peer-review process”. Cinema journal, v. 56, n. 4, pp. 137-141. https://doi.org/10.1353/cj.2017.0049

Mittell, Jason (2016). "But Is any of this legal? Some notes about copyright and fair use". In: Keathley, Christian; Mittell, Jason (eds.). The videographic essay: Criticism in sound \& image. Montreal: Caboose. ISBN: 9781927852040

Morton, Drew (2017). "Beyond the essayistic: Defining the varied modal origins of videographic criticism". Cinema journal, v. 56, n. 4, pp. 130-36.

https://doi.org/10.1353/cj.2017.0050

Nentwich, Michael (2003). Cyberscience: Research in the age of the Internet. Vienna: Austrian Academy of Sciences Press. ISBN: 9783700131885

http://epub.oeaw.ac.at/3188-7inhalt

Pasquali, Matias (2007). "Video in science. Protocol videos: The implications for research and society". EMBO reports, v. 8, n. 8, pp. 712-716.

http://embor.embopress.org/content/8/8/712

Pochoda, Phil (2013). "The big one: The epistemic system break in scholarly monograph publishing". New media \& society, v. 15, n. 3, pp. 359-378.

https://doi.org/10.1177/1461444812465143

Stewart, James; Procter, Rob; Williams, Robin; Poschen, Meik (2013). "The role of academic publishers in shaping the development of web 2.0 services for scholarly communication". New media \& society, v. 15, n. 3, pp. 413-432.

https://doi.org/10.1177/1461444812465141

Stork, Matthias (2004). "Film studies with high production values: An interview with Janet Bergstrom on making and teaching audiovisual essays". Frames cinema journal.

http://framescinemajournal.com/article/film-studies-with-high-production-values

Sugimoto, Cassidy R.; Thelwall, Mike (2013). "Scholars on soap boxes: Science communication and dissemination in TED videos". Journal of American Society for Information Science and Technology, v. 64, n. 4, pp. 663-674.

https://doi.org/10.1002/asi.22764

Van-den-Berg, Thomas; Kiss, Miklós (2016). Film studies in motion. From audiovisual essay to academic research video. Scalar. http://scalar.usc.edu/works/film-studies-in-motion/index

Willinsky, John; Provençal, Johanne (2013). "The intellectual and institutional properties of learning: Historical reflections on patronage, autonomy, and transaction". New media \& society, v. 15, n. 3, pp. 398-412.

https://doi.org/10.1177/1461444812465142 